\title{
What is a Conspiracy Theory?
}

\section{Giulia Napolitano ${ }^{1}$ (D) $\cdot$ Kevin Reuter ${ }^{2}$}

Received: 4 June 2020 / Accepted: 20 July 2021

(c) The Author(s) 2021

\begin{abstract}
In much of the current academic and public discussion, conspiracy theories are portrayed as a negative phenomenon, linked to misinformation, mistrust in experts and institutions, and political propaganda. Rather surprisingly, however, philosophers working on this topic have been reluctant to incorporate a negatively evaluative aspect when either analyzing or engineering the concept conspiracy theory. In this paper, we present empirical data on the nature of the concept conspiracy theory from five studies designed to test the existence, prevalence and exact form of an evaluative dimension to the ordinary concept conspiracy theory. These results reveal that, while there is a descriptive concept of conspiracy theory, the predominant use of conspiracy theory is deeply evaluative, encoding information about epistemic deficiency and often also derogatory and disparaging information. On the basis of these results, we present a new strategy for engineering conspiracy theory to promote theoretical investigations and institutional discussions of this phenomenon. We argue for engineering conspiracy theory to encode an epistemic evaluation, and to introduce a descriptive expression — such as 'conspiratorial explanation' - to refer to the purely descriptive concept conspiracy theory.
\end{abstract}

\section{Introduction}

Discussions of conspiracy theories pervade internet forums, social media, and the news. In both public and academic discourse, conspiracy theories are often taken to undermine trust in institutions and to hinder the spread of information (for instance, Vermeule and Sunstein 2009; Dieguez et al. 2016), and to be used as instruments of

This work is fully collaborative.

M. Giulia Napolitano

mgnapoli@uci.edu

Kevin Reuter

kevin.reuter@uzh.ch

1 University of California, Irvine, 85 Humanities Instructional Building, Irvine, CA 92697, USA

2 University of Zurich, Zürichbergstrasse 43, 8044 Zürich, Switzerland 
political propaganda (Muirhead and Rosenblum 2019; Cassam 2019). Not surprisingly, the expression 'conspiracy theory' seems to carry with it a negative value. This manifests itself in various ways. Conspiracy theorists are often portrayed as irrational (Coady 2007), and few people are willing to apply the label 'conspiracy theory' to their own views (Wood and Douglas 2013:7). In fact, expressions such as 'this is just a conspiracy theory!' seem to be often employed to dismiss certain theories as rumors or speculations. In other words, 'conspiracy theory', at least on the face of it, seems to be a negatively loaded expression.

This feature is reflected in the academic discussion of conspiracy theories. Scholars have been interested in finding ways to minimize belief in conspiracy theories (for instance, Swami et al. 2014) and to understand which psychological factors drive belief in conspiracy theories (for instance, Bilewicz et al. 2015; Douglas et al. 2016; Swami et al. 2010; Swami 2012). Conspiracy theories are assumed in many academic discussions to be something which should not be believed, and they are considered akin to rumors (Berinsky 2015), false beliefs, and misinformation (Lewandowsky et al. 2012).

However, philosophers working on this topic have been reluctant to include an evaluative element when analyzing or engineering the concept conspiracy theory, instead advocating for purely neutral definitions. This paper challenges the methodological approach that has led philosophers to focus on neutral definitions, and it suggests a way forward that relies on empirical investigations of the ordinary concept conspiracy theory. Given how heavily the discussion over defining conspiracy theories relies on empirical assumptions about the ordinary meaning of the expression, especially about the relation between its evaluative and descriptive dimensions, it comes as a surprise that such empirical investigations have not been conducted on the ordinary use of the expression 'conspiracy theory'. ${ }^{1}$ In this paper, we present empirical data on the nature of the ordinary concept conspiracy theory in order to foster a more careful discussion of how it should be defined or engineered.

We start in Sect. 2 with a survey of the most prevalent accounts of conspiracy theory in the philosophical debate, and identify two different assumptions that have been made when defining conspiracy theory: (1) the ordinary concept conspiracy theory is predominantly descriptive; (2) the evaluative conspiracy theory serves the function of silencing warranted accusations of conspiring. In Sect. 3, we present five studies on the ordinary meaning of 'conspiracy theory'. Our studies show that, while some people seem to have a descriptive concept of conspiracy theory, the most widespread uses of the expression 'conspiracy theory' indicate the predominance of an evaluative concept. Moreover, the studies suggest a double dissociation between conspiracy and conspiracy theory: referring to a conspiracy is neither necessary nor sufficient for attributions of 'conspiracy theory'. In Sect. 4, we discuss

\footnotetext{
1 Wood (2016) investigates the consequences of labelling a theory 'conspiracy theory'. While this might provide some insight into the consequences of using this term, it does not constitute an analysis of it. Some remarks about the negative connotation of conspiracy theory have been made by Wood and Douglas (2013).
} 
some implications of these results for the existing accounts of conspiracy theory, and present our own strategy for an epistemically evaluative engineering.

\section{Defining Conspiracy Theory: Philosophical Methodology}

The philosophical literature on conspiracy theories includes a variety of attempts at defining conspiracy theory. We identify two general approaches, which we label as descriptive conceptual analysis and conceptual engineering. By descriptive conceptual analysis, we mean those analyses which aim to provide the meaning of a term, and which are acceptable only if they are consistent with our ordinary intuitions. These proposals typically make use of the method of cases-e.g., they consider cases that are publicly known as 'conspiracy theories' - and then try to identify the necessary and sufficient conditions that make something a conspiracy theory. We use the label conceptual engineering to include all of those revisionary approaches to defining 'conspiracy theory' which do not aim to match our intuitions about cases, but rather improve on the ordinary concept by defining conspiracy theory in a way that serves a certain theoretical or practical goal. Framing the issue in terms of conceptual engineering allows us to draw from a rich discussion about this philosophical methodology and the different approaches that fall under this label. We understand conceptual amelioration, or ameliorative analysis (Haslanger 2012, 2020), as a type of conceptual engineering aimed at improving social reality by focusing on the purposes or functions of concepts. Another popular method, explication, proceeds from an often vague, informal concept, to provide a more exact and fruitful one, with the aim of improving a theoretical discussion. ${ }^{2}$ Within the literature on conspiracy theories, we can recognize engineering attempts akin to both kinds. In this section, we employ the labels of analysis and engineering to review the different claims and methods from prominent authors, in order to pin down the empirical assumptions that help to justify their conclusions for defining conspiracy theory in a descriptive, neutral way. ${ }^{3}$

\subsection{Descriptive Conceptual Analysis}

The method of descriptive conceptual analysis for conspiracy theory, understood as the attempt to devise a definition which matches our folk intuitions about conspiracy theories, has most explicitly been defended by Räikkä (2018)—though under a different label. In providing a survey of the different proposals that have

\footnotetext{
2 For a comparison between explication and ameliorative analysis, see Dutilh Novaes (2020).

3 Our use of the notions of conceptual analysis and conceptual engineering relies on one possible understanding of these philosophical methods. While we employ these labels as a way to organize the recent philosophical debate on conspiracy theories, we are aware that the way in which we characterize the two approaches are neither exhaustive nor uncontroversial. For a discussion of conceptual analysis along the lines that we propose see Daly (2010). For a discussion of conceptual engineering approaches, see Burgess and Plunkett (2013a, b); Cappelen (2018); and the papers in Burgess, Cappelen and Plunkett (2020).
} 
been put forward for defining conspiracy theories, Räikkä identifies three different approaches: to narrow, expand, or preserve the ordinary meaning of 'conspiracy theory' (2018:207). He argues that, when focusing on the question of our handling of conspiracy theories in our societies, philosophers' understanding of conspiracy theories should try to approximate the ordinary language meaning of 'conspiracy theory'. The idea is that, given that the public interest for conspiracy theories is driven by the practical and political problems with those theories that are commonly labeled 'conspiracy theories', we should neither expand nor narrow the content of the ordinary concept, but rather we should try and give a definition of conspiracy theory that picks out the same object as ordinary language, to then determine whether conspiracy theories so understood are in fact a problem. According to Räikkä, conspiracy theories are explanations which usually satisfy two conditions: (i) the conflict criterion, i.e., an explanation is a conspiracy theory only if it is in conflict with a received explanation of the same event, and (ii) the conspiracy criterion, i.e., an explanation is a conspiracy theory only if it refers to a conspiracy or plot (Räikkä 2018: 210-213). These criteria are taken to be descriptive, and conspiracy theory is not taken to necessarily encode in ordinary language a negative evaluation. ${ }^{4}$

Even though in Räikkä (2018) we find the most explicit defense of the method of descriptive conceptual analysis as opposed to conceptual engineering of conspiracy theory, analyses of conspiracy theory have been proposed in the literature since its infancy. For instance, Coady (2003) argues that conspiracy theory should be defined as:

A conspiracy theory is a proposed explanation of an historical event, in which conspiracy (i.e., agents acting secretly in concert) has a significant causal role. Furthermore, the conspiracy postulated by the proposed explanation must be a conspiracy to bring about the historical event which it purports to explain. Finally, the proposed explanation must conflict with an "official" explanation of the same historical event. (Coady 2003: 201).

Similar to Räikkä's, Coady's definition includes a version of the conspiracy criterion, and a version of the conflict criterion. ${ }^{5}$ Another widely endorsed definition of conspiracy theory is Keeley's. For Keeley, a conspiracy theory is 'a proposed explanation of some historical event (or events) in terms of the significant causal agency of a relatively small group of persons - the conspirators-acting in secret' (1999: 116). Keeley's proposal does not include a conflict criterion, and only takes some version of the conspiracy criterion to be necessary and sufficient for conspiracy

\footnotetext{
$\overline{4}$ More recently Ichino \& Räikkä (2020) have included an additional evidence criterion, according to which a conspiracy theory 'offers insufficient evidence in support of the alternative explanation, so that the view is not considered as a competitive scientific theory or anything like that'. This addition makes their definition epistemically evaluative, and more in line with the findings of our study.

5 The conflict criterion might be thought to encode an evaluation. However, both Coady and Räikkä seem to understand the conflict criterion purely descriptively. Levy (2007) has taken the conflict criterion to be normative, putting it in relation to epistemic authorities.
} 
theory. ${ }^{6}$ These definitions have in common the fact that they take conspiracy theory to be a descriptive concept. In fact these authors agree that, from the criteria they identify, it does not follow that conspiracy theories are necessarily irrational, or that they should not be believed. The negative connotation ordinarily attached to conspiracy theories has often been interpreted in these discussions as a pragmatic feature of conspiracy theory. Pigden (2006) calls it the 'conventional wisdom'-the widespread, and yet mistaken, belief that we have an epistemic duty not to believe or investigate theories about conspiracies. Some other authors who have adopted neutral definitions have identified a subclass of conspiracy theories as irrational and have introduced negatively loaded expressions to refer to them-such as Unwarranted Conspiracy Theories (Keeley 1999), and Counterfact Conspiracy Theories (Feldman 2011).

Another element that the different analyses of conspiracy theory have in common is the methodology employed to identify the criteria. From a methodological point of view, these proposals identify the defining features of conspiracy theory by analysing popular theories which are usually labeled 'conspiracy theories' - such as: the theory that climate change is a hoax, and the theory that genetically manipulated foods cause health problems (Räikkä 2018); official and alternative accounts of the 9/11 attacks (Coady 2003); conspiracy theories associated with the Oklahoma City bombing (Keeley 1999); the theory according to which Barack Obama was not born in the US (Feldman 2011).

Even though these philosophers might be correct in identifying instances of conspiracy theories in the public discussion, the methodological choice of relying on putative representative examples of theories which are generally labeled 'conspiracy theories' risks being misleading when it comes to understanding the possible evaluative component of conspiracy theory. By looking at allegedly representative cases of conspiracy theories, and the properties that these theories share, it is difficult to identify speaker-sensitive evaluations. If, as we hypothesize, conspiracy theory is an evaluative concept, it is necessary to focus on what drives speakers' attributions of 'conspiracy theory', rather than on the features that famous conspiracy theories have in common.

The methodological choice of relying on famous theories known as 'conspiracy theories' might be one of the factors that led the authors discussed in this section to focus on neutral definitions. That is why, in this paper, we opted for different methods, chosen specifically to test for the existence of an evaluative dimension, and investigate its prevalence and characteristics.

\footnotetext{
${ }^{6}$ Other attempts to descriptively analyse the concept conspiracy theory which include a conspiracy criterion, sometimes supplemented with a descriptive conflict criterion, include Cohnitz (2018), Feldman (2011), Harris (2018), Mandik (2007) and Pigden (2007). A different proposal comes from Cassam (2019). He introduces the label 'Conspiracy Theory' with capital C and capital T to refer to a subset of theories about conspiracies which display additional epistemically problematic features.
} 


\subsection{Conceptual Engineering}

While projects of descriptive conceptual analysis have largely taken the expression 'conspiracy theory' to pick out a descriptive concept in ordinary language, the situation is different for engineering proposals. In fact, some philosophers have acknowledged that conspiracy theory has a negatively evaluative meaning, but have argued that the ordinary meaning ought to be changed. ${ }^{7}$

Coady argues, on the basis of examples from the scholarly and public debate, that the expressions 'conspiracy theory' and 'conspiracy theorist' have multiple meanings, which are typically used equivocally in the academic and political debate. In particular, according to his analysis, 'conspiracy theory' is both employed pejoratively to dismiss certain theories and descriptively to indicate theories about conspiracies. The equivocation that follows from this semantic ambiguity has negative consequences both for our theorizing about conspiracy theories and for the social environment in which these terms are used (Coady 2018a: 292). In fact, it allows for dismissing theories about conspiracies, even when these theories are epistemically justified. For Coady, the pejorative expression 'conspiracy theory' is employed to dismiss conspiracy accusations, and it constitutes a form of epistemic injustice against people who profess believing theories about conspiracies (2018a: 300). For this reason, he argues that we should refrain from using the expression 'conspiracy theory' and neighboring ones (see also Coady 2007, 2012, 2018b).

Other philosophers seem to share Coady's worry that the label 'conspiracy theory' can lead to the illegitimate dismissal of warranted theories about conspiracies. Basham and Dentith (2016) have claimed that the pejorative meaning of 'conspiracy theory' is routinely abused by politicians and institutions to dismiss unwanted conspiracy allegations. They write:

Much contemporary media, most political leaders and some social scientists insist that "conspiracy theory" must mean something automatically false or irrational. Yet our historians show it does not and never did. The pejorative use of "conspiracy theory" is a use of mere convenience. The official account of 9/11 is, after all, a conspiracy theory: the hijackers conspired to fly airplanes into buildings in New York City, Washington, and elsewhere. That's a conspiracy theory. Was it called that? Not by mainstream media, or most political leaders. But it was, just the same. Any pejorative use of "conspiracy theory" is intellectually suspect, as is its convenient absence when governmental institutions use conspiracy theories to promote their goals. We are facing a phase of social manipulation, one which some academics wish to portray and empower

\footnotetext{
7 None of these philosophers have used the expression 'conceptual engineering' to describe their approach to conspiracy theory, and have instead talked about stipulative definitions. We believe that the stipulative definitions discussed here can be seen as instances of engineering, in the very broad sense of the expression adopted here, as assessing and improving representational devices (Cappelen 2018). Moreover, our notion of engineering includes both conceptual revision for practical purposes, such as improving our social and political environment, and for theoretical purposes, such as providing a more fruitful notion to improve a scientific debate.
} 
in a way so that it cannot impugn our hierarchies of power, but only defend them. The only conspiracy theories permitted will be official conspiracy theories. They will not be called "conspiracy theories." But their explanatory method will be indistinguishable. (Basham and Dentith 2016:15)

Differently from Coady, who argues that the ambiguity of 'conspiracy theory' calls for eliminating the expression altogether, Basham and Dentith advocate for conceptual change towards a neutral definition of conspiracy theory. They argue that, in both academic and public discussions of conspiracy theories, the evaluative meaning should be abandoned in favor of the descriptive sense of conspiracy theory as any explanation of events that cites a conspiracy (for instance, Dentith 2014; Basham 2018a, b).

The arguments for changing the meaning of 'conspiracy theory' reviewed so far have in common that the expression 'conspiracy theory' is assumed to have a negative effect on our political environments. ${ }^{8}$ 'Conspiracy theory' is taken to be a powerful label that can be exploited to ridicule accusations of conspiring, allowing conspiracies to continue unnoticed. In this respect, Basham, Coady, and Dentith's proposals for engineering conspiracy theory can be considered as ameliorative in their intent: they aim at conceptual change primarily to improve the effects of the use of this expression on our society. ${ }^{9}$

Dentith (2014, 2018b) also offers a different argument for engineering conspiracy theory neutrally. They argue that a neutral and minimal definition of conspiracy theory as an explanation of an event which involves a conspiracy is best suited to promote theoretical discussions about the rationality of believing conspiracy theories (2014:123). Dentith's motivation for proposing such a definition is theoretical, rather than practical. Their aim is to devise a stipulative definition which can be better employed within the academic discussion of conspiracy theories, and they seem to have the academic community as a target for their definition. In this sense, Dentith's proposal is different from the other engineering approaches discussed so far. However, Dentith does not seem concerned with matching our folk intuitions about the concept conspiracy theory, and thus we take their proposal to be an instance of engineering in the sense adopted in this paper-albeit one closer to an explication rather than an amelioration. In the rest of the paper, we will focus on the ameliorative approaches which are guided by social and political concerns, and leave out Dentith's theoretically motivated engineering. But their proposal will be discussed again in Sect. 4.2.2.

Even though the engineering proposals defended by authors such as Coady, and Basham and Dentith (in their joint work) are ameliorative, and explictly presented as a shift from the way in which the expression is ordinarily used, their proposals are still bound by assumptions regarding the ordinary concept conspiracy theory and its function in ordinary language. First, they rely on the assumption that the current

\footnotetext{
8 See also Basham and Dentith 2016; Dentith 2018a, b; Basham 2018a; Hagen 2018; Orr and Dentith 2018.

${ }^{9}$ For a discussion of these effects on society, see Stokes (2018), and the responses to his paper in the same volume by Basham and Dentith.
} 
uses of the label 'conspiracy theory' are defective in that they make people prone to dismissing charges of conspiracies without evaluating them-possibly because the expression is ambiguous. Moreover, they seem to be assuming that the main function that the evaluative conspiracy theory plays in society is that of serving the interest of the powerful by discouraging people from investigating conspiracies. If they did not subscribe to this idea, one might argue against their proposal that, even though eliminating the evaluative concept would help promoting societal goods, it would also generate undesirable conceptual loss in our representational resources. Moreover, adopting a neutral definition for investigating conspiracy theories in academic settings would run the risk of driving a wedge between the academic and the public discussion of this phenomenon. And, given the relevance of the phenomenon of conspiracy theories to the public debate, this detachment of the academic discussion from ordinary talk of conspiracy theories could lead to further problems of equivocation and confusion. So, even though the ordinary meaning of 'conspiracy theory' is only indirectly relevant to these ameliorative proposals, they are still relying on crucial empirical assumptions regarding the ordinary use of this expression.

While the academic and political uses of the expression have been more thoroughly documented (Husting and Orr 2007; Coady 2012, 2018a), the ordinary use of conspiracy theory has not been systematically investigated empirically, and these philosophers have primarily relied on examples and personal observations on the use of the expression.

Basham takes Wood (2016) to provide empirical evidence that conspiracy theory does not have a negative connotation:

Michael Wood (2016) shows what we already know; "conspiracy theory" possesses no negative connotation except as residue among certain academic, media, and political elites. (Basham 2018b: 40)

However, Wood's study only shows that labelling a theory a 'conspiracy theory' does not lead people to reduce their belief in that theory, compared to when that theory, with the same exact content, is called in a different way. The experiments found 'no evidence of a negative effect of calling something a conspiracy theory' (Wood 2016: 702). But this result does not necessarily imply that the meaning of the expression is neutral in ordinary language. In any case, this study speaks against the worry expressed by Basham and others that the label 'conspiracy theory' could be used to dismiss warranted conspiracy accusations. If labelling a theory 'conspiracy theory' does not affect belief in that theory, it is hard to see how this label could be employed for inducing people to dismiss certain warranted theories about conspiracies.

The empirical studies we present in the next section suggest that conspiracy theory has an evaluative meaning which is prevalent in ordinary language. They also confirm the worry that conspiracy theory is ambiguous. Ultimately, our studies provide empirical support for the claim that the authors reviewed in this section make: that conspiracy theory should be engineered. However, they also provide insight into the function of the ordinary evaluative concept, and end up putting significant pressure on the specific proposal of engineering conspiracy theory neutrally, or eliminating the label altogether. 


\section{Empirical Studies}

While many philosophers have either taken the meaning of 'conspiracy theory' to be descriptive, or argued that the evaluative meaning should be eliminated, no one has so far investigated the folk concept of conspiracy theory empirically. Instead, philosophers have largely focused on individual cases that they have often considered to be representative of the general phenomenon. In what follows, we opted for a different methodological approach. In five individual studies, we empirically investigated the uniqueness, prevalence, and the form of the evaluative sense of conspiracy theory. Our studies are divided into two sections. In Sect. 3.1, we aim to show that the dominant meaning of 'conspiracy theory' is evaluative. To show this, we used three different experimental paradigms (semantic feature production task, vignette study, corpus analysis). In Sect. 3.2, we designed two studies that indicate a double dissociation between conspiracy and conspiracy theory. In other words, we show that neither do the application conditions for the term 'conspiracy theory' include a conspiracy condition, nor do people think a conspiracy warrants the application of the term 'conspiracy theory'.

\subsection{The Evaluative Sense of Conspiracy Theory}

In three individual studies, we empirically investigated the evaluative sense of conspiracy theory.

\subsubsection{Study 1a: Semantic Features of Conspiracy Theory}

Semantic feature production tasks are standardly used to collect those semantic features that are encoded within a concept (McRae et al. 2005). For instance, common features that people come up with for the term 'robin' are 'flying', 'has wings', 'lays eggs', 'a bird', etc. The aim of Study 1a was to collect those features that are encoded within the concept conspiracy theory.

While standard semantic feature production tasks have been argued to provide access into word meaning (Medin 1989) and predict semantic processing in various tasks (Pexman et al. 2003), the results cannot straightforwardly be taken as evidence that the dominantly produced features are necessary for the application of the concept. Instead, some features might be merely salient (but not necessary) features of the concept at stake. To overcome this limitation, we decided to use a slight variation of the semantic feature production task (see e.g., Reuter et al. 2020), in which participants are asked to produce necessary features, and not just any features that come to mind.

50 participants $\left(M_{\text {age }}=33.94 ; 20\right.$ females, none indicating non-binary gender, all English native speakers) were recruited on Amazon's Mechanical Turk and were paid a small fee for taking part in the study. They were asked to note down three necessary conditions for something to be regarded a conspiracy theory. 
Vignette Think for a moment about what it means to be a conspiracy theory. Please state three conditions that you believe are necessary for something to be a conspiracy theory.

In total, 150 responses were collected. Table 1 shows the responses for the first 25 participants.

We were particularly interested in features expressing descriptive aspects of conspiracy theories, like 'some sort of cover up' (or simply 'cover up' or likewise), 'it involves a conspiracy' (or simply 'conspiracy' or likewise), etc. Additionally, we wanted to know how many people would note down features indicating an evaluative sense of conspiracy theory. When we scanned the responses for evaluative features, we noticed that people came up with terms that fall very roughly into two different categories: (i) terms that indicate epistemic deficiencies, like 'untrue', 'no evidence', 'far-fetched', and 'not provable'; (ii) terms that are more generally dismissive and pejorative, like 'crazy', 'paranoid', and even moral terms like 'evil'. Features from both evaluative categories were so common among many participants that we decided to ask three independent coders (x / y / z) to classify all 150 terms into three groups: terms indicating epistemic deficiencies, strongly disparaging terms, and all others.

The high number of participants responding with evaluative terms, including terms expressing epistemic deficiencies as well as derogatory terms, suggests that the predominant sense of conspiracy theory is evaluative: A substantial majority $(66 \% / 74 \% / 70 \%)$ does not entertain a notion of conspiracy theory that is primarily descriptive. Instead, most people seem to encode evaluative features in their concept of conspiracy theory. However, not all participants who think normatively about conspiracy theories go so far in entertaining a sense of the term 'conspiracy theory' that indicates a strong pejorative attitude. Nonetheless, (32\% / 38\% / 32\%) of the participants not only thought that conspiracy theories are epistemically deficient theories, but considered them to be crazy or ridiculous explanations, or similarly. In regards to the descriptive terms, eleven participants wrote that a conspiracy theory involves a cover-up, four participants responded with 'conspiracy' or likewise, and a mere single person stated that a conspiracy theory is claimed to be false by officials. This suggests that the cover-up criterion might be a more prevalent descriptive criterion compared to the more widely discussed conspiracy and conflict criteria. While the results of Study 1a provide us with a window into the semantic representation of the concept of conspiracy theory, we need to be careful not to overstate the evidence, but rather take the results as one important piece in our argument. We therefore investigated the extent to which participants hold an evaluative concept of conspiracy theory using a classical vignette study.

\subsubsection{Study 1b: The Prevalence of the Evaluative Meaning}

The aim of Study $1 \mathrm{~b}$ was to examine more directly the extent to which people entertain an evaluative meaning of that concept. 111 participants were recruited on Amazon's Mechanical Turk. 10 participants had to be excluded, because they either indicated that English was not their native tongue, or they did not finish the survey. The average age of the remaining 101 participants was $M_{\text {age }}=37.81$ and consisted of 46 
Table 1 Responses of the first 25 participants in the semantic feature production task

\begin{tabular}{|c|c|c|c|}
\hline Participant & 1 st term & 2nd term & 3rd term \\
\hline Person1 & Questions & Vagueness & Coverup \\
\hline Person2 & Shady dealings. & lies & Manipulation of an event . \\
\hline Person3 & More theory than fact & Ties to government coverup & Farfetched \\
\hline Person4 & Lack of evidence & It involves someone powerful & Hard to believe \\
\hline Person5 & Realistic & Evil & Factual \\
\hline Person6 & UNTRUE & ILLOGICAL & IRRATIONAL \\
\hline Person7 & No answer to the question & Many people believe it & No evidence to refute it \\
\hline Person8 & Controversial & Mysterious & Weird \\
\hline Person9 & Needs to be a conspiracy & Powerful people & Unlikely to be true \\
\hline Person 10 & ... Secret group involved & Power must be involved . & Deceit or deception . \\
\hline Person 11 & Facts & Obsession & Curiousity \\
\hline Person12 & Not a popular belief. & Science doesn't back it up. & Controversial. \\
\hline Person13 & 1 group believe something & 2 nd group is against the $1 \mathrm{st}$. & Published / known fact \\
\hline Person 14 & Cult Following & Grasping evidence & Outlandish claim \\
\hline Person 15 & unproven info & No consensus & Lack scientific data \\
\hline Person 16 & Over the top & Crazy & Out there \\
\hline Person 17 & Made up & Paranoid & Outlandish \\
\hline Person 18 & Multiple people believe it & It's controversial & Has some evidence to back it \\
\hline Person 19 & Uncertainty & Lack of concrete facts & People believe it \\
\hline Person20 & Extreme theory & Intrigue & Espionage \\
\hline Person 21 & Not provable & Insane & Random \\
\hline Person22 & Sensational & Substantial coverup & Crazy or crazy sounding \\
\hline Person23 & Lots of people believe it & The government is ... part of it & At least 3 people follow it \\
\hline Person24 & Not widely believed & Hidden actors/motiives & Some sort of cover up \\
\hline Person 25 & Motive & Challenge & Crazy people \\
\hline
\end{tabular}

females, 55 males, and none indicating non-binary gender. All participants were randomly presented with one of the following two short vignettes:

Imagine Peter makes the following statement:

Peter Maria says that the theory I've heard about is a conspiracy theory. / Maria says that the theory I've heard about is a scientific theory.

The vignette featuring 'scientific theory' was included as a control condition, in order to eliminate the possibility that the way we asked the question would bias people into thinking negatively about Maria's attitude. The participants were then presented with the following statement "Maria's attitude towards the theory that Peter has heard about is:" and asked to rate Maria's attitude on a 7-point Likert scale anchored at ' -3 ' meaning 'negative', ' 0 ' meaning 'neutral', and ' 3 ' meaning 'positive'. The average rating for the condition featuring 'conspiracy theory' was $M_{a v}=-1.06$ (SD = 1.77), and was significantly below the midpoint of ' 0 ', $\mathrm{t}(51)=-4.32, p<0.001$. The mean value for the control condition (scientific theory) was $M_{a v}=+1.29$ ( $\left.\mathrm{SD}=1.02\right)$, and was significantly above the midpoint: 
$\mathrm{t}(48)=8.81, \mathrm{p}<0.001$. Of the 52 participants who were randomly assigned to the conspiracy vignette, 33 participants gave a negative rating, and 11 participants gave a positive rating. Figure 1 shows the average ratings for both conditions.

The results of Study $1 \mathrm{~b}$ reveal that a substantial majority of the participants selected negative values. Comparing the results of Study 1a with Study 1b, a rather uniform pictures evolves, according to which around $2 / 3 \mathrm{rds}$ of the population seem to think that the concept conspiracy theory is negatively evaluative.

\subsubsection{Study 1c: Corpus Analysis}

Studies 1a and 1b have two shortcomings: First, they test people's use of terms in isolation from their natural context. Second, the experimental setup might have interfered with getting reliable results on the meaning of the target expressions. Within the last decade, philosophers have started to use tools from corpus linguistics to examine terms within large corpora (see, e.g., Sytsma et al. 2019). These tools avoid both these shortcomings by investigating how terms like 'conspiracy theory' are used by ordinary language speakers in natural contexts.

In Studies 1a and 1b, we collected data showing that many people entertain evaluative features when thinking about conspiracy theories. If the dominant meaning of 'conspiracy theory' were indeed evaluative, we should be able to find further support for this claim when analyzing large corpora. As we are primarily interested in the way that ordinary people use the term in natural contexts, a corpus using posts and discussion notes from reddit, the social news website, was built (no specific subreddits were selected, such that the selected comments are unlikely to have been tilted towards a certain readership and/or distorted by specific jargon). ${ }^{10}$ We then searched for and collected comments featuring the term 'conspiracy theory/ies/ists' in a time span of 120 days (25th December 2019-22nd April 2020), and ended up with 68'640 comments. ${ }^{11}$

In order to investigate the evaluative dimension of conspiracy theory, we recorded all adjectives that appear directly in front of 'conspiracy theory' like 'crazy conspiracy theory'. If the expression is used in a predominantly neutral way, then we should find a balanced representation of positive, neutral and negative adjectives, e.g., 'plausible/political/crazy conspiracy theory'. In contrast, if the concept is mostly used negatively, we would expect those adjectives to be strongly negative as well.

Among the 50 most frequent adjectives-covering $42 \%$ of all uses we collected -25 adjectives were negative, 17 neutral, and 8 positive. Table 2 (left hand side) lists the 10 most frequent adjectives that occur in front of "conspiracy theory'. These results strongly suggest that conspiracy theories are not predominantly

\footnotetext{
10 We would like to thank Lucien Baumgartner for his support with the corpus-analytic study.

11 Given the limited time span of our corpus analysis, we cannot be sure that the way people talked about conspiracy theories in 2019 and 2020 is representative of the years before and the years to come. Some conspiracy theories most talked about in these two years might have features that other conspiracy theories discussed at other times do not have.
} 


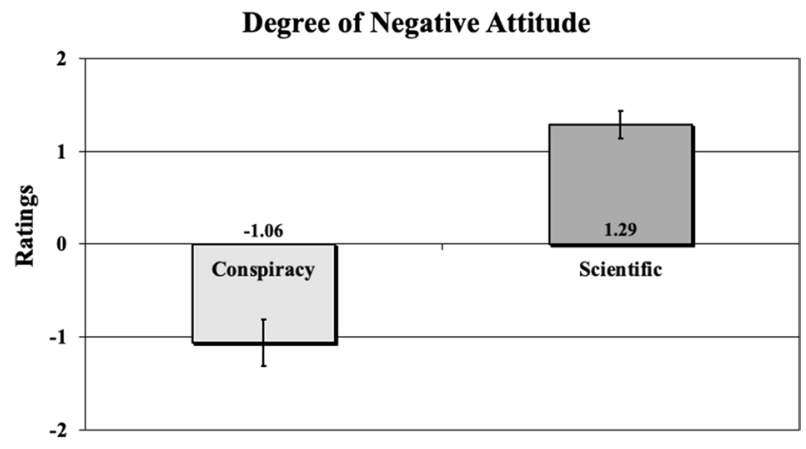

Fig. 1 Mean values of the ratings in Study 2. Error bars indicate standard error around the means

considered to be neutral theories, but very often considered to be inherently negative.

However, against this conclusion, a plausible objection might be made. The evaluative terms we recorded might not be indicative of the meaning of 'conspiracy theory' but rather suggest that the meaning was modified by those terms in order to express an evaluation that is not part of 'conspiracy theory' itself. However, we believe we have good reasons to dismiss this alternative reading. If negative adjectives merely modify but don't intensify the evaluative aspect of 'conspiracy theory', then we should not find a major difference between 'conspiracy theory' and a clearly neutral term like 'theory'. We therefore conducted an analysis of the term 'theory' using the same method as above. The results are markedly different (see also Table 2 (right hand side)). Among the 50 most frequent adjectives, only 6 were negative, 13 positive, and 31 neutral.

\subsubsection{Summary of the Results}

In Study 1a, we used the semantic feature production task to detail the terms most commonly associated with 'conspiracy theory'. The results suggest that the concept conspiracy theory is often considered evaluative. In Study 1b, we asked a direct and simple question about whether the content of the concept conspiracy theory is evaluative. Most people believe the term 'conspiracy theory' to have a negative meaning. For Study 1c, we built a corpus from the social media agglomeration website reddit in order to examine the term 'conspiracy theory' in natural language use. Our data analysis revealed a strong co-occurrence of negative adjectives with the term 'conspiracy theory', thereby confirming our previous studies that involved online participants.

\subsection{Double Dissociation of Conspiracy Theory and Conspiracy}

While the first three studies indicate the existence and dominance of an evaluative meaning of 'conspiracy theory' among laypeople, we have not directly investigated the role of the descriptive features that many proponents of purely descriptive 
Table 2 A list of the 10 most frequent adjectives in front of 'conspiracy theory' and 'theory'

\begin{tabular}{|c|c|c|c|c|c|}
\hline \multicolumn{3}{|c|}{ Conspiracy Theory } & \multicolumn{3}{|l|}{ Theory } \\
\hline Term & Number & Percentage $(\%)$ & Term & Number & Percentage $(\%)$ \\
\hline Crazy & 684 & 4.1 & Good & 872 & 5.3 \\
\hline Good & 460 & 2.8 & Interesting & 752 & 4.6 \\
\hline Stupid & 377 & 2.3 & Economic & 704 & 4.3 \\
\hline Ridiculous & 342 & 2.1 & Scientific & 586 & 3.6 \\
\hline Wild & 272 & 1.6 & Political & 456 & 2.8 \\
\hline Insane & 267 & 1.6 & Great & 450 & 2.7 \\
\hline Dumb & 238 & 1.4 & Personal & 387 & 2.4 \\
\hline Racist & 230 & 1.4 & Critical & 336 & 2.0 \\
\hline Favorite & 208 & 1.3 & Different & 252 & 1.5 \\
\hline Weird & 208 & 1.3 & Popular & 247 & 1.5 \\
\hline
\end{tabular}

accounts have defended. Unfortunately, testing the importance of all the proposed descriptive features is beyond the scope of this paper. We have therefore decided to examine what seems to many philosophers to be the core descriptive aspect. More specifically, we tested two hypotheses: First, people are willing to call an explanation a 'conspiracy theory', even in situations in which no conspiracy has taken place. ${ }^{12}$ Second, people tend not to call a claim a 'conspiracy theory', even if a conspiracy has taken place. In other words, we aim to show a double dissociation between conspiracy theory and conspiracy.

\subsubsection{Study 2a: Conspiracy Theory Without Conspiracy}

In Study 2a, we tested whether people are willing to call a claim a 'conspiracy theory' even though no conspiracy has taken place. We decided to manipulate two different aspects. First, we aimed to measure the effect that a real conspiracy would have on people's willingness to call a claim a 'conspiracy theory'. Thus, in the conspiracy condition Conspiracy, we specified that "the Incas destroyed most of the evidence, and made it look as if they had built the temple themselves." In the no-conspiracy condition Lost in Time, we stated that "everyone knew about it back then, ... most of the evidence of it got lost over time." Second, the vignettes either featured an explanation Aliens that was epistemically highly deficient (an explanation that referred to aliens), or an explanation Chancas that was not the official explanation, but not too far-fetched (an explanation that referred to the Chanca tribe).

All participants were randomly assigned to one of four conditions: Aliens Conspiracy, Aliens Lost in Time, Chancas Conspiracy, Chancas Lost in Time. Here are

$\overline{{ }^{12} \text { A similar hypothesis has been }}$ considered, though not investigated empirically, by Walker (2018). 
the two vignettes (Aliens Lost in Time \& Chancas Lost in Time (in Square brackets)) we used for the no-conspiracy conditions.

Imagine you overhear the following conversation:

Luke I think that the famous Coricancha temple was built by aliens [by the Chancas] and not by the Incas.

Anna Are you kidding? And how do you explain that we know nothing about this?

Luke Well, I believe that everyone knew about it back then, but the temple was built such a long time ago, so most of the evidence of it got lost over time. ${ }^{13}$

Anna This is a conspiracy theory.

Participants were then asked how fitting it is that Anna used the expression 'conspiracy theory', and rated the fittingness on a 7-point Likert scale anchored at ' -3 ', meaning 'not at all fitting' and ' 3 ' meaning 'Absolutely fitting'. 161 participants (66 male, 91 female, 2 non-binary; $M_{\text {age }}=34.19$ ) were recruited on Prolific Academic and were paid a small fee for taking part in the experiment.

The average ratings of the four vignettes are depicted in Fig. 2. We conducted a $2 \times 2$ ANOVA with Ratings as the dependent variable and two independent variables: Creatures (Aliens, Chancas) and Condition (Conspiracy, Lost in Time). Both these factors were significant, Creatures, $\mathrm{F}(1,156)=35.78, \mathrm{p}<0.001$, and Condition, $\mathrm{F}(1,156)=27.82, \mathrm{p}<0.001$. There was also a small interaction between those two factors, $\mathrm{F}(1,156)=4.74, \mathrm{p}=0.031$. Furthermore, mean ratings for all four conditions were significantly different from the midpoint of ' 0 '.

The results show that in the condition Aliens Lost in Time, people are willing to call an explanation a conspiracy theory $\left(M_{a v}=1.25\right)$ despite the fact that no conspiracy had taken place, but "everyone knew about it". When the explanation instead

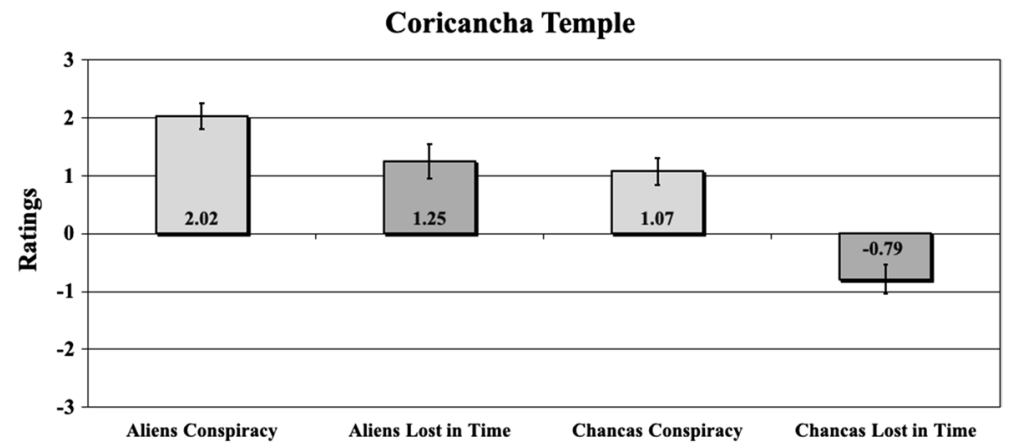

Fig. 2 Mean values of the ratings in Study 2a. Error bars indicate standard error around the means

\footnotetext{
13 In the two conspiracy conditions, the second statement of Luke was "Well, I believe the Aliens built [Incas recruited the Chancas to build] the temple. But the Incas did not want the world to know that they did not build the Coricancha temple themselves, so they destroyed most of the evidence, and made it look as if they had built the temple themselves."
} 
featured a more plausible story Chancas Lost in Time, participants did not endorse the claim that the explanation was a conspiracy theory. Now, admittedly, whether or not the Incas conspired, did play a significant role in boosting the average responses. Thus, we should note that people were more likely to call an explanation a conspiracy theory if a conspiracy had taken place, ceteris paribus. Nonetheless, the results do indicate that conspiracy theories do not need to include a conspiracy. ${ }^{14}$

\subsubsection{Study 2b: Conspiracy Without Conspiracy Theory}

In Study 2b, we intended to investigate the reverse claim, namely, whether people would be reluctant to call a claim a conspiracy theory, even if it featured a conspiracy. To this end, we used a variant of the Watergate scandal, but set in Argentina in the 1980s. We hypothesized that whether or not people call a claim a conspiracy theory was less dependent on whether the claim included a conspiracy, but rather whether the claim was true or false. We therefore manipulated two factors: The truth condition of the claim at stake was varied between true and false. We also suspected that the officialness of the story could have an important effect. Thus, we also manipulated whether or not the wide majority of Argentinians today believed the claim to be true.

163 participants were recruited on Prolific (57 male, 105 female, 1 non-binary; $\left.M_{\text {age }}=34.54\right)$. They were then randomly assigned to one of four conditions: true and official, true and unofficial, false and official, false and unofficial. The vignettes read as follows:

In the 1980s in Argentina, some people broke into the building of a political party and stole documents. Soon, the following claim was made:

Claim: The president himself had ordered this crime in order to gain advantage over his opponents in the upcoming election campaign process and tried to cover this up.

Here are two facts about that case.

1. The claim is true [false]. (the president ordered [did not order] the crime and tried to cover up his involvement.)

2. Today the wide majority of Argentinians believe the claim to be true [false].

\footnotetext{
${ }^{14}$ We would like to thank a reviewer for this journal for highlighting two concerns with this experiment. First, the storyline resembles conspiracy theories about the mythical island Atlantis. Second, participants might have inferred that Luke was told about the alternative explanation by people who might intend to cover-up the actual evidence. Both aspects could have led participants to make an implicit inference that there was indeed some conspiracy going on. While we have taken reasonable precaution to avoid such implications, e.g., by having Luke say that "I believe that ..." as if it was his own reasoning that got him to this 'insight' about the Incas, we cannot fully rule out that these aspects have had an effect on our participants.
} 
All participants were then asked to answer the question 'Would you call the claim a conspiracy theory?' on a 7-point Likert scale ranging from '-3' labelled as 'Definitely not' to ' 3 ' labelled as 'Definitely yes'. The average results for all four conditions are displayed in Fig. 3. We conducted a 2 x 2 ANOVA with Ratings as the dependent variable and Truth (true, false) and Officialness (official, unofficial) as independent variables. Truth was a significant factor, $\mathrm{F}(1,159)=$ 134.86, $\mathrm{p}<0.001$, whereas Officialness was not, $\mathrm{F}(1,159)=6.10, \mathrm{p}=0.130$. T-tests revealed that the results of both true \& official and true \& unofficial were significantly below the midpoints, and both false \& official and false \& unofficial were significantly above the midpoint of ' 0 ' (all ps $<0.001$ ).

In both conditions in which the claim at stake was true, the majority of the participants would not regard the claim a conspiracy theory despite the claim involving a conspiracy at the highest level. Only when the claim was false did people positively state that this was a conspiracy theory. Whether or not the claim was officially accepted played no significant role, although a greater number of participants might have resulted in a significant effect. Why would people call a claim a 'conspiracy theory' if the claim was false? Presumably, it is not the truth or falsity that matters, but rather that a claim that is false is not likely to have the right epistemic virtues, e.g., no facts, lack of evidence, far-fetched. At least this would be in accordance with the results of Studies 1a-c. Finding out more about the role these factors play is an exciting avenue for future research.

\subsubsection{Summary of the Results}

In Study 2a, we tested a specific account of the descriptive meaning of 'conspiracy theory'. According to many theorists, conspiracy theories satisfy the conspiracy criterion, i.e., the explanation at stake features a conspiracy. The majority of the participants considered it appropriate to apply the term 'conspiracy theory' to an explanation that features no conspiracy. The outcome of Study $2 b$ revealed that the reverse claim also holds: Even if an explanation clearly includes a conspiracy, it is not considered to be a conspiracy theory, if the claim is true. In other words, our results in Sect. 3.2 suggest that conspiracy and conspiracy theory can be doubly dissociated.

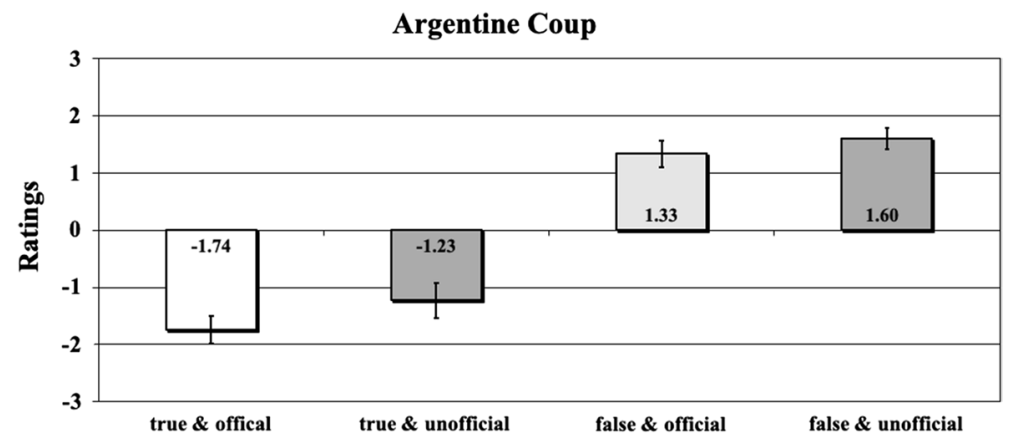

Fig. 3 Mean values of the ratings in Study 2b. Error bars indicate standard error around the means 


\section{General Discussion}

In the empirical part of this paper, we examined the content of the ordinary meaning of 'conspiracy theory'. Our main goal was to find out whether this concept is evaluative or predominantly descriptive. In order to investigate this issue, we used five studies using three different empirical methods.

The results of all five studies reveal a rather uniform picture, according to which the ordinary meaning of the expression 'conspiracy theory' is predominantly evaluative. This is not to say that the term 'conspiracy theory' is not ambiguous: around one-third of the population seems to entertain a notion of conspiracy theory that is primarily descriptive.

Importantly, the predominant evaluative meaning of 'conspiracy theory' is not just an add-on on top of some descriptive content. Instead, the results of Studies $2 \mathrm{a} \& 2 \mathrm{~b}$ suggest that the evaluative meaning is largely independent of some of the widely-discussed descriptive criteria. The independence of both usages provides further evidence that the evaluative content of the term 'conspiracy theory' is not conveyed pragmatically but is part of the meaning of the term. ${ }^{15}$

Of course, the results of our studies cannot be easily generalized to other cultures, languages, and other times. In fact, we consider it quite likely that the meaning of the term 'conspiracy theory' has changed substantially during the last few decades. The frequency with which the term 'conspiracy theory' is used has risen sharply since the 1980s and continues to rise (see the Google Books Ngram of "conspiracy theory' here https://books.google.com/ngrams/graph?content=conspiracy+theory\& year_start $=1800 \&$ year_end $=2019 \&$ corpus $=26 \&$ direct_url $=\mathrm{t} 1 \% 3 \mathrm{~B} \% 2 \mathrm{Cconspira}$ cy $\% 20$ theory $\% 3 \mathrm{~B} \% 2 \mathrm{Cc} 0$ ). A cross-temporal analysis of how the term 'conspiracy theory' might have changed during the last few decades is thus highly desirable.

In the remaining two sections of this paper, we discuss how best to interpret the data we collected in the empirical studies and the consequences for philosophical theorizing about conspiracy theories. We first provide an analysis of the evaluative concept conspiracy theory using the framework of thick concepts. We then subsequently examine the prospects for various ways of defining and engineering the concept of conspiracy theory.

\subsection{The Evaluative Meaning of Conspiracy Theory}

The results of the five studies revealed that the dominant meaning of 'conspiracy theory' is not purely descriptive. Instead, we have presented empirical evidence that evaluative content is encoded as part of the concept conspiracy theory. But what exactly then is the meaning of the term 'conspiracy theory'? The simplest suggestion would be to hold that an equivalent expression to 'conspiracy theory' is 'bad

\footnotetext{
15 This result is in line with the history of the expression 'conspiracy theory' defended by McKenzieMcHargh (2018), according to whom two different concepts-a descriptive one, and an evaluative oneemerged in the Nineteenth and Twentieth century. However, the alternative possibility that an evaluative concept emerged from the descriptive one is not ruled out.
} 
theory' or perhaps 'bad explanation'. Accordingly, in the context of talking about a theory or an explanation, we merely communicate our disapproval of the theory by calling the explanation a 'conspiracy theory'. While this suggestion is in line with the results of Study 1b, it is too simple a suggestion and cannot be squared with the results of the other studies. Our results do indeed indicate that people believe conspiracy theories to be bad theories. They do not, however, show that people think that all bad theories are properly called conspiracy theories: Conspiracy theories are bad in a more specific respect. To get a better picture of what this amounts to, let us briefly highlight some differences among evaluative concepts that have been discussed in the literature.

Evaluative concepts are usefully divided into thin concepts, thick concepts, and dual character concepts. Thin evaluative concepts like awesome and bad evaluate without specifying the way in which the target is evaluated. For example, if Helen says that Tom's behavior is bad, you do not know (without further information) whether it is bad because he lied, because he was risking lives, because he was only in for his own advantage, etc.

Thick concepts work differently: Concepts like crazy, beautiful, and unjustified have both evaluative and descriptive content. Their use evaluates positively or negatively, but also specifies the content that is under evaluation. For example, if Helen states that Tom's behavior is crazy, then we can infer more than that Helen thinks of Tom's behavior as bad. She tells us that what is bad about his behavior is that his behavior makes little sense in one way or another. If she were to say that Tom's behavior is generous, then she would tell us that Tom was giving more than expected and that his behavior is good in virtue of giving more than expected. ${ }^{16}$

Given the existence and rich stock of thick evaluative concepts in our languages, a more sophisticated proposal would be to say that the composite term 'conspiracy theory' has a thick evaluative meaning. In other words, people not only express their disapproval of a theory (or an explanation) by calling it 'conspiracy theory', they also communicate the descriptive aspect under which it is considered to be bad. Fortunately, the results of Studies 1a and 1c allow us to draw some conclusions about what the descriptive aspect might be that is evaluated negatively. When we asked people to tell us the necessary conditions for something to be a conspiracy theory, they did not simply note down 'bad', 'terrible' or other thin evaluative terms. Instead, many participants wrote down thick evaluative terms. Those evaluative responses were categorized into two groups: those attributes that indicate epistemic deficiency, and those indicative of a more general pejorative attitude. Very common responses in the first group were 'unjustified', 'false', and 'non-scientific'. The second group consisted of a wide variety of terms. On the one hand, terms like 'obsessed' and 'evil' express moral disapproval. On the other hand, terms like 'insane', 'crazy' and 'ridiculous' are not moral terms, but are derogatory terms that are most likely produced because of the epistemic deficiencies of conspiracy

\footnotetext{
${ }^{16}$ Dual character concepts are similar to thick concepts in that they encode both descriptive as well as evaluative information. In contrast to thick concepts, however, the evaluative and descriptive dimensions are doubly dissociatable. For a more detailed exposition of dual character concepts, see Reuter (2019).
} 
theories. Such an interpretation is further supported by Study 1c, in which adjectives were recorded that occur directly before 'conspiracy theory'.

Let us start with the first set of words expressing epistemic deficiency without derogatory meaning. A plausible interpretation of the high frequency with which terms like 'not provable', 'unjustified', and 'far-fetched' were mentioned, is that a conspiracy theory is considered a theory that has insufficient epistemic justification, is not in the business of being epistemically justified, or is epistemically deficient in some other way. Consequently, an equivalent expression to 'conspiracy theory' is not just 'bad theory' but rather 'epistemically deficient theory'. Of course, ordinary people will hardly use these two expressions interchangeably, but the proposal seems to aptly summarize that people not only consider conspiracy theories bad, but provide some descriptive content under which they are considered to be bad.

The second set of words goes beyond mere epistemic deficiency. Several participants provided responses that communicate strong disapproval, sometimes of a moral type. The majority of pejorative terms were of a non-moral sort, like 'crazy' and 'ridiculous'. In fact, these terms were not only frequent in the semantic feature production task, the corpus analysis revealed a frequent and strong co-occurrence with 'conspiracy theory'. These terms are often used pejoratively in an epistemic sense. Importantly, epistemic deficiency does not automatically warrant a pejorative attitude in all cases. Many theories are unproven or unprovable (string theory), or unjustified (phlogiston theory). We suspect though that very few people would go so far in calling them crazy or ridiculous. In other words, we can distinguish theories that are (at least in some sense) bad because they are epistemically deficient (including string theory), and theories that are epistemically bad and likely to be disparaged.

What might these further aspects be that often trigger a derogatory attitude? A plausible suggestion is that many people consider conspiracy theories to be crazy and ridiculous because they satisfy some additional criterion, like having no epistemic justification or resist disconfirmation in light of any counter-evidence (Napolitano, 2021). What exactly those criteria are is an interesting and open question. It is very likely that these criteria are not fixed but vary from person to person. Unfortunately, a more precise answer goes beyond what is inside the data we collected.

\subsection{Towards a Definition of Conspiracy Theory}

The results of the empirical studies allow us to draw some conclusions regarding not only what the ordinary meaning of 'conspiracy theory' is, but also how conspiracy theory ought to be defined.

Our studies suggest that the ordinary language term has a predominant evaluative component. If, as Räikkä (2018) argues, philosophers should approximate the dominant ordinary language meaning of 'conspiracy theory' as much as possible in order to foster an academic and political discussion of conspiracy theories which maintains the same subject as ordinary language, conspiracy theory should incorporate evaluative features, and it should not incorporate a conspiracy criterion as a necessary condition. If a proposed descriptive conceptual analysis of conspiracy 
theory left out an evaluative aspect, then it would not be a satisfactory analysis of the predominant concept of conspiracy theory.

\subsubsection{Engineering Conspiracy Theory}

The results from our studies have consequences for determining whether descriptive conceptual analysis is indeed the best method to achieve the goals that Räikkä has in mind for fostering a rigorous theoretical and institutional discussion of conspiracy theories which is close to everyday language. The range of evaluations encoded in conspiracy theory and the double dissociation of conspiracy and conspiracy theory might constitute a reason against sticking to the ordinary meaning of the term-at least for a scientific or institutional discussion of the problem of conspiracy theories. While belief in bad theories is something that academics and institutions might be interested in understanding and minimizing, it seems to be way too broad to constitute the object of targeted scientific investigation and public intervention. This is a reason to advocate for engineering the evaluative conspiracy theory into a sharper concept, rather than employing descriptive conceptual analysis. ${ }^{17}$

In addition to recommending engineering as the best method for promoting a rigorous academic and institutional discussion of the phenomenon of people believing absurd theories, the empirical results of our studies have implications for the existing ameliorative proposals which were reviewed in Sect. 2. Those proposals were driven by the worry that the current use of 'conspiracy theory' might lead to the silencing of warranted investigations of conspiracies, and might thus allow powerful people to exploit semantic defects of the concept conspiracy theory for their advantage. Some results of our empirical studies seem to speak against this worry: the evaluative concept conspiracy theory does not seem to apply to all theories about conspiracies, and attributions of 'conspiracy theory' seem to be driven by assessments of the theory. ${ }^{18}$

\footnotetext{
17 The method of explication, famously described by Carnap (1950) is especially suited to this task, as it aims at promoting the exactness and fruitfulness of a concept while maintaining similarity with its ordinary meaning. For a discussion of Carnapian explication see Maher (2007), Carus (2008), Justus (2012) and Brun (2016).

18 While our results seem to be in tension with the findings of Wood (2016) about the lack of a negative effect of labeling a theory 'conspiracy theory', there are reasons to think that they are not. Wood's experiments indeed found 'no evidence of a negative effect of calling something a conspiracy theory' (Wood 2016: 702). However, two things should be noted: In Wood's main Study 2, the two conditions differed in whether the claims were labelled as 'conspiracy theory' and 'corruption allegation'. As allegations are also presented without any proofs, perhaps a more neutral label would have resulted in substantial differences. Second, and more importantly, the story the participants read featured information about the "latest development in a growing political scandal" as well as a "Canadian political watchdog group calling for an investigation". Hence, participants are given information that strongly suggests that the claim under investigation is not as outrageous and far-fetched as many other claims that run under the label 'conspiracy theory'. So, they might disagree on labelling the content presented as a 'conspiracy theory', and they might be assessing the plausibility and likelihood of the conspiracy allegations independently of whether they are labeled 'conspiracy theory'. A similar explanation could be given for Wood's Study 1. While this might explain away the apparent tension between our results and Wood's (2016), more studies should be conducted to investigate under which circumstances labelling a claim a 'conspiracy theory' has an effect and under which it has no such effect.
} 
However, our studies also indicate that the concept is ambiguous. Even though only a minority of the participants in Study 1a indicated only descriptive features, this result is not irrelevant. It suggests that some people possess a purely descriptive concept of conspiracy theory. Moreover, our studies show that there is not a core concept conspiracy theory that is then supplemented with a more or less negative attitude. The descriptive and evaluative concept conspiracy theory seem to be distinct concepts - the evaluative concept does not include the core feature of the descriptive concept, which is involving a conspiracy. This ambiguity might lead to equivocations and unwarranted inferences when reasoning about conspiracy theories, and it would motivate a different kind of conceptual engineering approach, as amelioration aimed at promoting better political and social environments, and not just at improving theoretical discussions of conspiracy theories.

While our studies lend support to the claims made by Coady, Basham, and Dentith that conspiracy theory should be ameliorated, they also put pressure on their specific proposal of eliminating the evaluative concept of conspiracy theory altogether, even granting that in conceptual amelioration the engineered concept need not be necessarily similar to the ordinary one in meaning-amelioration opting instead for the continuity with the ordinary concept's function or functions in our practices and discourses (Haslanger 2012:224-225; Dutilh Novaes 2020). The predominance of the evaluative concept conspiracy theory, and its independence from the descriptive one, shows that the choice of some academics to focus on conspiracy theories as a problem, and the attempt to explain belief in such theories in terms of psychological or sociological factors is not necessarily a choice driven by hidden political motives to silence the investigation of conspiracies in our societies. The evaluative concept conspiracy theory is prevalent in ordinary thought and language, and attributions of 'conspiracy theory' seem to be driven by an assessment of the target theory, even in the absence of a conspiracy component. Thus, the function that this concept serves in academic practices and discourses cannot be silencing warranted conspiracy accusations. ${ }^{19}$ More likely, the main function of the evaluative concept is to single out a phenomenon of irrational belief in certain absurd theories. While an ambiguous use of 'conspiracy theory' might lead to equivocations and silencing, and should therefore be corrected for, the evaluative concept alone does not seem to serve this function, and the complete elimination of the evaluative conspiracy theory would interfere with the progress of outlining and understanding a phenomenon which has attracted the interest of many scholars and institutions.

\footnotetext{
19 Cf. Basham and Dentith (2016), Dentith (2018a, 2018b), Basham (2018a), Hagen (2018) and Orr and Dentith (2018). One possible way to object to our analysis would be to grant that the derogatory use of conspiracy theory is not the exclusive use of powerful elites of academics and politicians, but claim that the derogatory use of conspiracy theory is the result of the repeated efforts by these groups to derogate theories about conspiracies by employing the label 'conspiracy theory'. However, our studies lend support to the claim that the evaluative component of conspiracy theory is a feature of the meaning of the expression, rather than a pragmatic implication of its use. So, even if the origin of the meaning of conspiracy theory was related to the manipulative intention of academics and politicians, this would not change the fact that the meaning of 'conspiracy theory', nowadays, is predominantly evaluative, it does not apply to all theories about conspiracies, and is driven by evaluations of the target theory. Accordingly, the function of the concept would have changed over time.
} 


\subsubsection{Sketching a Solution}

One of the findings of our studies suggests a way forward. We have observed that the evaluative concept conspiracy theory encodes a wide range of evaluations, which we classified in two categories: epistemic evaluations and derogatory attitudes. Our proposal is to reserve the label 'conspiracy theory' to refer only to the epistemically evaluative conspiracy theory - while introducing a new expression, such as 'conspiratorial explanation', to refer to the descriptive 'theories which involve conspiracies'.

The more pejorative sense, expressed by terms like 'crazy' and 'insane', encodes highly derogatory information and contains little descriptive content. Since the rules that govern the application of this pejorative label are highly subjective, and of difficult evaluation, this sense of conspiracy theory should be eliminated for promoting better discussions of the topic of conspiracy theories. On the other hand, epistemic evaluations refer to inter-subjective standards, and they are richer in descriptive content. Once appropriately characterized and specified, the epistemic criteria constitutive of conspiracy theory could be employed to assess different theories and determine the correct application of the concept. The more the criteria that identify the epistemically evaluative conspiracy theory are clearly specified, the less the label 'conspiracy theory' could be exploited to dismiss theories which do not display the epistemic defects necessary for correctly applying the concept.

Moreover, if the epistemic flaws identified as constitutive of conspiracy theory implied the irrationality of believing conspiracy theories, and not just a minor epistemic deficiency, the epistemically evaluative concept would maintain its current derogatory usage. In academic and institutional discussions, it would enable those approaches that look at the non-epistemic reasons for believing conspiracy theories-such as psychological or sociological reasons-and the institutional attempts at minimizing belief in conspiracy theories. If conspiracy theory was employed to refer to a certain type of irrational theory, this would justify explaining beliefs in these theories by appeal to non-epistemic factors, and trying to minimize such beliefs. And if the epistemic defects were appropriately described, these scholars could more easily identify the theories on which to focus in their investigations (cf. Cohnitz 2018:358). ${ }^{20}$

A possible concern with our engineering strategy is that epistemically evaluative definitions would create more variance in their applications than descriptive ones, and this would be a disadvantage of these definitions. If conspiracy theory incorporated an epistemic evaluation, one might worry that whether a theory counts as a 'conspiracy theory' would depend on who believes it and their epistemic grounds. The first thing to notice about this is that not all epistemically evaluative proposals need necessarily be subject-dependent. Theories, i.e., sets of propositions, too can have epistemic deficiencies-for instance, they can be false, or inconsistent, or

\footnotetext{
${ }^{20}$ Admittedly, the strategy we suggest is more suited for technical discussions of the topic than it is for ordinary usage. However, the ordinary evaluative concept conspiracy theory which encodes both epistemic evaluations and more pejorative attitudes might not be problematic in ordinary language, in the absence of an ambiguous descriptive concept.
} 
contrary to what independently identified experts believe, and so on. So, while some specific proposals might have the consequence that a theory is a conspiracy theory depending on who believes it (e.g., Napolitano 2021), not all epistemically evaluative proposals are subject to this worry. Secondly, the increase in variance in attributions of conspiracy theory is not necessarily a disadvantage of a proposal, and might in fact be an advantage if one is interested-as many scholars and most institutions seem to be-in understanding conspiracy theories as a phenomenon of irrational belief.

The introduction of a different expression like conspiratorial explanation to refer to the descriptive concept eliminates the ambiguity which generated the risk of equivocating theories about conspiracies and bad theories. ${ }^{21}$ Moreover, the descriptive conspiratorial explanation - rather than a descriptive engineering of conspiracy theory - could be employed for those philosophical projects which necessitate a neutral definition, such as comparing explanations that involve conspiracies to other types of explanations, which have typically been the object of investigation in philosophy of science (Keeley 2019); or investigating the rationality of theories which involve conspiracies (Dentith 2014, 2018b). The descriptive 'conspiratorial explanation' could serve the same aim which motivated theoretical engineering projects such as Dentith's, while maintaining the evaluative sense of 'conspiracy theory' to preserve talk of conspiracy theories in the negative sense. While the use of the neutral 'conspiratorial explanation' alongside the evaluative 'conspiracy theory' might seem to complicate the academic debate on conspiracy theories, it would actually make clear that different debates about conspiracy theories have been talking about two different things all along. ${ }^{22}$

How exactly the epistemically evaluative conspiracy theory should be engineered is to be determined through philosophical arguments, and through an assessment of the effects that different engineered concepts would have on both our theorizing about conspiracy theories, and our political and social treatment of warranted conspiracy accusations. ${ }^{23}$ It is possible that different engineered concepts will be best employed in different projects, and not a single definition will serve both the theoretical and the societal aims equally well. Our proposal regards only the direction which should be taken by philosophers trying to define conspiracy theory in a way that both promotes the scientific investigations of conspiracy theories and the public

\footnotetext{
21 Another possible proposal for a neutral label, albeit a narrower one, comes from DeHaven-Smith (2006).

22 A related issue is whether our proposal of adopting two expressions to refer to the descriptive and the evaluative concept gives rise to worries regarding implementation. One specific worry might be that the descriptive 'conspiratorial explanation' is a rather technical expression, unlikely to be picked up in ordinary language. However, we believe that our proposal is primarily targeted at academic discussions, rather than at society at large, where the implementation of a new concept like this should be easier. Moreover, implementation is a serious concern for any engineering proposal, not just the one discussed here. For a discussion of the implementation challenge, and possible solutions see Cappelen and Plunkett (2020); Andow (2021) and Koch (2021).

${ }^{23}$ For a specific engineering proposal which follows this strategy, see Napolitano (2021). Cassam (2019) can also be interpreted as a proposal along the same lines: his account of conspiracy theories is epistemically evaluative and suited to investigations of conspiracy theories as instruments of political propaganda.
} 
discussion of how to deal with them, and at the same time avoids possible negative effects on our political environments.

\section{Conclusion}

A central question in the philosophical discussion about conspiracy theories focuses on what the meaning of the expression 'conspiracy theory' is and what it should be. In this paper, we addressed this question by employing some of the methods of experimental philosophy. In five studies, we have shown that the assumption that conspiracy theory is primarily descriptive does not withstand empirical scrutiny. Moreover, our studies show that conspiracy and conspiracy theory are doubly dissociable: people sometimes do not attribute the label 'conspiracy theory' to theories which involve conspiracies, while they do sometimes attribute it to theories which do not involve any conspiracy. These results put pressure on the neutral definitions of 'conspiracy theory' which are currently widely endorsed in the philosophical debate-both those which are proposed as descriptive analyses and those which are proposed as ameliorations of the ordinary concept conspiracy theory. We argued that the best strategy for defining conspiracy theory is to engineer the evaluative concept to encode specific epistemic deficiencies.

Acknowledgments This research was presented at the University College Dublin Online Conference on Conspiracy Theories, the Experimental Philosophy Conference Prague, ECAP 10, the EXTRA.5 Research Colloquium at Ruhr University Bochum, and the CONCEPT colloquium at the University of Cologne. We would like to thank the audiences as well as Sven Bernecker, Daniel Cohnitz, Ethan Landes, Juha Räikkä, and Pascale Willemsen for their very helpful feedback. Many thanks also to the editors of this journal and four anonymous reviewers who provided us with excellent comments on previous versions of this paper. This research was supported by the Swiss National Science Foundation SNSF (PCEFP1 181082).

Open Access This article is licensed under a Creative Commons Attribution 4.0 International License, which permits use, sharing, adaptation, distribution and reproduction in any medium or format, as long as you give appropriate credit to the original author(s) and the source, provide a link to the Creative Commons licence, and indicate if changes were made. The images or other third party material in this article are included in the article's Creative Commons licence, unless indicated otherwise in a credit line to the material. If material is not included in the article's Creative Commons licence and your intended use is not permitted by statutory regulation or exceeds the permitted use, you will need to obtain permission directly from the copyright holder. To view a copy of this licence, visit http://creativecommons.org/licen ses/by/4.0/.

\section{References}

Basham, L. (2018a). Social scientists and pathologizing conspiracy theorizing. In M. R. X. Dentith (Ed.), Taking conspiracy theories seriously (pp. 95-108). London: Rowman and Littlefield.

Basham, L. (2018b). Conspiracy theory particularism, both epistemic and moral, versus generalism. In M. R. X. Dentith (Ed.), Taking conspiracy theories seriously (pp. 39-58). London: Rowman and Littlefield.

Basham, L., \& Dentith, M. R. X. (2016). Social sciences conspiracy theory panic: Now they want to cure everyone. Social Epistemology Review and Reply Collective, 5(10), 12-19. 
Berinsky, A. (2015). Rumors and Health Care Reform: Experiments in Political Misinformation. British Journal of Political Science, FirstView, 47, 1-22.

Bilewicz, M., Cichocka, A., \& Soral, W. (Eds.). (2015). The psychology of conspiracy. New York, NY: Routledge.

Brun, G. (2016). Explication as a method of conceptual re-engineering. Erkenntnis, 81, 1211-1241.

Burgess, A., \& Plunkett, D. (2013a). Conceptual ethics I. Philosophy Compass, 8(12), 1091-1101.

Burgess, A., \& Plunkett, D. (2013b). Conceptual ethics II. Philosophy Compass, 8(12), 1102-1110.

Burgess, A., Cappelen, H., \& Plunkett, D. (Eds.). (2020). Conceptual engineering and conceptual ethics. Oxford University Press.

Cappelen, H. (2018). Fixing language: an essay on conceptual engineering. Oxford University Press.

Cappelen, H., \& Plunkett, D. (2020). A guided tour of conceptual engineering and conceptual ethics. In A. Burgess, H. Cappelen, \& D. Plunkett (Eds.), Conceptual engineering and conceptual ethics (pp. 1-26). Oxford: Oxford Universty Press.

Carnap, R. (1971[1950]). Logical foundations of probability). Chicago, Illinois: University of Chicago Press.

Carus, A. (2008). Carnap and twentieth-century thought: Explication as enlightenment. Cambridge: Cambridge University Press.

Cassam, Q. (2019). Conspiracy theories. Oxford: Polity Press.

Coady, D. (2003). Conspiracy theories and official stories. International Journal of Applied Philosophy, 17(2), 197-209.

Coady, D. (2007). Are conspiracy theorists irrational? Episteme, 4(2), 193-204.

Coady, D. (2012). What to believe now: Applying epistemology to contemporary issues. Wiley-Blackwell.

Coady, D. (2018a). Cass Sunstein and Adrian Vermeule on conspiracy theories. Argumenta, 3(2), 291-302.

Coady, D. (2018b). Conspiracy-baiting and anti-rumour campaigns as propaganda. In M. R. X. Dentith (Ed.), Taking Conspiracy Theories Seriously (pp. 171-187). London: Rowman and Littlefield.

Cohnitz, D. (2018). On the rationality of conspiracy theories. Croatian Journal of Philosophy, 18(2), $351-365$.

Daly, C. (2010). An introduction to philosophical methods. Peterborough: Broadview Press.

DeHaven-Smith, L. (2006). When political crimes are inside jobs: detecting state crimes against democracy. Administrative Theory \& Praxis, 28(3), 330-355.

Dentith, M. R. X. (2014). The philosophy of conspiracy theories. United Kingdom: Palgrave Macmillan.

Dentith, M. R. X. (2017). Conspiracy theories on the basis of the evidence. Synthese, 196, 1-19.

Dentith, M. R. X. (Ed.). (2018). Taking conspiracy theories seriously. Rowman \& Littlefield International.

Dentith, M. R. X. (2018a). The conspiracy theory theorists and their attitude towards conspiracy theory-introduction to section two. Taking conspiracy theories seriously (pp. 73-77). London: Rowman and Littlefield.

Dentith, M. R. X. (2018b). Taking conspiracy theories seriously and investigating them. Taking conspiracy theories seriously (pp. 217-225). London: Rowman and Littlefield.

Dentith, M. R. X. (2018c). What particularism about conspiracies entails. In M. R. X. Dentith (Ed.), Taking conspiracy theories seriously (pp. 59-70). London: Rowman and Littlefield.

Dieguez, S., Bronner, G., Campion-Vincent, V., Delouvée, S., Gauvrit, N., Lantian, A., \& WagnerEgger, P. (2016). 'They' Respond: Comments on Basham et al'.s 'Social Science's ConspiracyTheory Panic: Now They Want to Cure Everyone. Social Epistemology Review and Reply Collective, 5(12), 20-39.

Douglas, K., Sutton, R. M., Callan, M. J., Dawtry, R. J., \& Harvey, A. J. (2016). Someone is pulling the strings: Hypersensitive agency detection and belief in conspiracy theories. Thinking \& Reasoning, 22(1), 57-77.

Douglas, K. M., Uscinski, J. E., Sutton, R. M., Cichocka, A., Nefes, T., Ang, C. S., \& Deravi, F. (2019). Understanding conspiracy theories. Political Psychology, 40(S1), 3-35.

Dutilh Novaes, C. (2020). Carnapian explication and ameliorative analysis: a systematic comparison. Synthese, 197, 1011-1034.

Feldman, S. (2011). Counterfact conspiracy theories. International Journal of Applied Philosophy, $21(1), 15-24$. 
Harris, K. (2018). What's epistemically wrong with conspiracy theorising? Royal Institute of Philosophy Supplement, 84, 235-257.

Hagen, K. (2018). Conspiracy theorists and social scientists. In M. R. X. Dentith (Ed.), Taking conspiracy theories seriously (pp. 125-139). London: Rowman and Littlefield.

Haslanger, S. (2012). Resisting reality. Oxford: Oxford University Press.

Haslanger, S. (2020). Going on, not in the same way. In A. Burgess, H. Cappelen, \& D. Plunkett (Eds.), Conceptual engineering and conceptual ethics. (pp. 230-260). Oxford University Press.

Husting, G., \& Orr, M. (2007). Dangerous machinery: Conspiracy theorist as a transpersonal strategy of exclusion. Symbolic Interaction, 30, 127-150.

Ichino, A., \& Räikkä, J. (2020). Non-Doxastic Conspiracy Theories. Argumenta, 1-18.

Justus, J. (2012). Carnap on concept determination: Methodology for philosophy of science. European Journal for Philosophy of Science, 2, 161-179.

Keeley, B. L. (1999). Of conspiracy theories. Journal of philosophy, 96, 109-126.

Keeley, B. L. (2019). The credulity of conspiracy theorists: Conspiratorial, scientific \& religious explanation compared. In Uscinski (Ed.), Conspiracy theories and the people who believe them. (pp. 422-431) Oxford: Oxford University Press.

Koch, S. (2019). Carnapian explications, experimental philosophy, and fruitful concepts. Inquiry: An Interdisciplinary Journal of Philosophy, 62(6), 700-717.

Koch, S. (2021). There is no dilemma for conceptual engineering. Reply to Max Deutsch. Philosophical Studies, 178, 2279-2291.

Levy, N. (2007). Radically socialized knowledge and conspiracy theories. Episteme, 4(2), 181-192.

Lewandowsky, S., Ecker, U. K. H., Seifert, C. M., Schwarz, N., \& Cook, J. (2012). Misinformation and its correction: Continued influence and successful debiasing. Psychological Science in the Public Interest, 13, 106-31.

Maher, P. (2007). Explication defended. Studia Logica, 86, 331-341.

McKenzie-McHargh, A. (2018). Conspiracy theory: The nineteenth-century prehistory of a twentiethcentury concept. In Uscinski (Ed.), Conspiracy theories and the people who believe them. (pp. 62-81) Oxford: Oxford University Press.

McRae, K., Cree, G., Seidenberg, M., \& McNorgan, C. (2005). Semantic feature production norms for a large set of living and nonliving things. Behavior Research Methods, 37(4), 547-559.

Medin, D. (1989). Concepts and conceptual structure. American Psychologist, 44, 1469-1481.

Muirhead, R., \& Rosenblum, N. (2019). A lot of people are saying: The new conspiracism and the assault on democracy. Princeton: Princeton University Press.

Napolitano, M. G. (2021). Conspiracy Theories and Evidential Self-Insulation. In S. Bernecker, A. Floweree \& T. Grundmann (Eds.), The Epistemology of Fake News. Oxford University Press.

Orr, M., \& Dentith, M. R. X. (2018). Clearing up some conceptual confusions about conspiracy theory theorizing. In M. R. X. Dentith (Ed.), Taking conspiracy theories seriously (pp. 141-153). London: Rowman and Littlefield.

Pexman, P., Holyk, G., \& Monfils, M.-H. (2003). Number of features effects and semantic processing. Memory \& Cognition, 31, 842-855.

Pigden, C. (2007). Conspiracy theories and the conventional wisdom. Episteme, 4(2), 219-232. https:// doi.org/10.3366/epi.2007.4.2.219.

Räikkä, J. (2018). Conspiracies and conspiracy theories. Argumenta, 3(2), 205-216.

Reuter, K. (2019). Dual character concepts. Philosophy Compass., 14, e12557.

Reuter, K., Löschke, J., \& Betzler, M. (2020). What is a colleague? The descriptive and normative dimension of a dual character concept. Philosophical Psychology, 33(7), 997-1017.

Swami, V., Chamorro-Premuzic, T., \& Furnham, A. (2010). Unanswered questions: A preliminary investigation of personality and individual difference predictors of $9 / 11$ conspiracist beliefs. Applied Cognitive Psychology, 24, 749-761. https://doi.org/10.1002/acp.1583

Swami, V. (2012). Social psychological origins of conspiracy theories: The case of the Jewish conspiracy theory in Malaysia. Frontiers in Psychology, 2012(3), 280.

Swami, V., Voracek, M., Stieger, S., Tran, U. S., \& Furnham, A. (2014). Analytic thinking reduces belief in conspiracy theories. Cognition., 133(3), 572-585. https://doi.org/10.1016/j.cognition. 2014.08.006

Stokes, P. (2018). Conspiracy theory and the perils of pure particularism. In M. R. X. Dentith (Ed.), Taking conspiracy theories seriously (pp. 25-38). London: Rowman and Littlefield. 
Sytsma, J., Bluhm, R., Willemsen, P., \& Reuter, K. (2019). Causation attributions and corpus analysis. In E. Fischer \& M. Curtis (Eds.), Methodological advances in experimental philosophy (pp. 209-238). London: Bloomsbury Academic.

Vermeule, A. \& Sunstein, C. (2009). Conspiracy Theories: Causes and Cures. Political Philosophy, $17(2), 202-227$.

Walker, J. (2018). What we mean when we say "conspiracy theory"' In J. Uscinski (Ed.), Conspiracy theories and the people who believe them (pp. 53-61). Oxford University Press.

Wood, M. J. (2016). Some dare call it conspiracy: Labeling something a conspiracy theory does not reduce belief in it. Political Psychology, 37, 695-705.

Wood, M. J., \& Douglas, K. M. (2013). "What about building 7?'” A social psychological study of online discussion of 9/11 conspiracy theories. Frontiers in Psychology, 4, 409.

Publisher's Note Springer Nature remains neutral with regard to jurisdictional claims in published maps and institutional affiliations. 